3) Durch Ausziehen des Guajakharzes in der Kälte, mittelst Maceration.

Das erste dieser Extracte ist reich an Geruch, das $z w e i t e$ ist es weniger, das dritte ist fast geruchlos.

Das erste Extract gab mehr Säure als das zweite, das dritte enthielt gar keine.

Unter diesen Umständen und wenn das Guajakharz seine Eigenschaften einem eigenthïmlichen wohlriechenden Harze und der darin befindlichen Säure verdanlst, mufs die Vorschrift des Codex den Voryug haben.

Das, was ich balsamisches Harz nemne, ist der Aetherauszug des Guajakextractes. Dieses Extract in Alkohol von $50^{\circ} \mathrm{C}$. aufgelöst und mit Zuckersaft vermischt, griebt eine Flüssigkeit vom Geruch and Geschmack der Vanille.

Anfser dem balsamischen Harze enthält das Guajakextract noch ein anderes Harz, eine schwarze in Alkohol unlösliche, in Ammoniak lösliche Materie, Kalksalze und eine merkliche Menge Eisen ${ }^{*}$ ).

\title{
Ueber das Guajakharz; von
}

Pelletier.

Schreiben an Hrm. Cap.

Paris, den 2. Juni 1811

Ich habe gehöri, dars eine Notiz über das Guajak. harz der Redaction des .Journal de Pharmacie eingesandi. worden ist. Seit einiger Zeit, wie mehre meiner Collegen wissen, bin ich mit einer Arbeit über diesen Gegenstanı beschäftigt, die aber noch nicht beendet ist. Un indessen nicht ganz das Verdienst meiner Versuche zu verlieren, erlauben Sie mir, Ihnen einige der von mir erhaltenen Resultate mitzutheilen.

Ich stellte zuerst eine Elenentaranaly'se des reinen

*) Journ, de Pharmac. XXVII, 38I. VgI. die Versuche Jahr's in diesem Arch, 2. R. Bt. XXI, 254. Bd. XXIII, 280 11. f., so wit" die Versuche Landerer's, die noch friher angestellt wurden, ebendaselbst, und die eine eigenthimliche Säure im Guajals betreffetr

D. Red. 
durchsichtigen Guajakharzes in Lacrymis an. Die 'Zusammensetzung dieses Harzes ist:

Kohlenstoff ...71,000
Wasserstoff.. 7,033
Sauerstoff. . .21,967

100.

Jedoch kann auch selbst das reine Guajakharz in Lacrymis nicht als ein unmittelbarer Bestandtheil angesehen werden; es enthält ohngefähr $\frac{1}{10}$ eines in Ammoniak lüslichen Harzes und eine gelbe färbende Materie.

Zur Darstelluug des Guajacins, nämlich des eigenthïmlichen Stoffs des Guajaks, giebt es mehre Wege. Am angemessensten scheint es mir, die Guajalharztinctur mit einer spirituösen Auflösung von essigsaurem Bleioxyd zu fallen, die man theilweise zusetzt, damit man die Niederschläge fractioniren und die letzten wegwerfen kann. Der Niederschlag wird erst mit Wasser und dann mit Alkohol ausgewaschen, hierauf in Wasser verbreitet und dann durch Schwefelwasserstoff zersetzt, endlich scheidet man das Guajacin ron dem Schwefelblei durch Alliohol ab.

Das Guajacin läfst sich auch darstellen, wenn man Guajaktinctur mit Kallhydrat behandelt; es bildet sich eine Verbindung von Guajacin und Kalk, aus der man diese Substanz leicht abscheiden kann.

Das Guajacin besitzt im hohen Grade die Eigenschaft, an der Luft unter Einflufs des Lichtes sich blau zu färben, eine Eigenschaft, die von Wollaston und Biot $u$. a. studirt worden ist. Die Färbung geschieht schneller in lufthaltigem als in luftfreiem Wasser, in diesen Fällen aber unter Entwicklung von Wasserstoff. Körper, die eine grofse Anzichung zum Sauerstorr haben, als Schwetlichtsäure, Schwefel wasserstoff, schwefelsaures Eisenoxydul, Zinnchlorür u.s. w., entfärben das gebläute Guajak, Aussetzung an Luft und Licht bringen die blaue Farbe wieder hervor.

Feuchtes Chlor und Chlorwasser machen das Guaja- 
cin ebenfalls blau, darch einen Ueberschuls von Chlor wird es grïn und darauf gelb. In diesem grünen und gelben Zustande ist es zersetzt; in dem blauen Zustande ist es nur oxydirt und kann durch Schwefelwasserstoff u. s. w. wieder entfïrbt werden.

Mit der Elementaranalyse und Bestimmung der Sätligungscapacität des Guajacins bin ich noch beschäftigf, und obwohl es mit den salzfähigen Basen sich verbindet, so stehe ich doch an, es als eine Säure zu betrachten. Ich könnte noch mehre Puncte berühren, doch ich beschränke mich auf Vorstehendes, welches nur den $Z$ weck haben soll zu bemerken, dafs ich mit der Untersuchnng des Guajaks mich beschäftige ${ }^{*}$ ).

\section{Ueber die Bereitung des Spiritus nitrica aethereus; \\ von \\ Dr. Geiseler, \\ Apotheker zu Königsberg in der Neumark.}

Fis ist bekannt, dafs der nach der Preufsischen Plarmakopöe bereitete Salpeteräther-Weingeist oft nur sehr wenig Salpeteräther enthält, es ist aber auch bekaunt, dafs die Vermehrung des Aethergehaltes unter Befolgung der angeführten Vorschrift von Umständen abhängigg ist, die nicht in der Gewalt des Arbeiters stehen. Dazu kommt noch, dafs die genannte Pharmakopïe vorschreibt, rohe Salyetersäure, wie sie im Handel vorkommt, zu verwenden, die, abgesehen von ihrer Reinheit, bald 1.,20, bald 1,30 specifisch schwer ist und deren wechselnde specifische Dichtignkeit auf die wechselnde Beschaffenheit des damit dargestellten Präparats nicht ohne Einflurs sein kann.

Davon ausgehend nun, dafs die Bildung mancher. zusammengesetzter Aetherarten leichter geschieht, wenn der aus Aetherschwefelsäure sich abscheidende Aether

*) Journ. de Pharmac. XXVII, 386. 